University of Nebraska - Lincoln

DigitalCommons@University of Nebraska - Lincoln

Faculty Publications, Department of Psychology

Psychology, Department of

10-1998

\title{
Evaluating Measures of Family History of Alcoholism: Density versus Dichotomy
}

\author{
Scott F. Stoltenberg \\ University of Michigan, Ann Arbor, sstoltenberg2@unl.edu \\ Sharon A. Mudd \\ University of Michigan, Ann Arbor \\ Frederic C. Blow \\ University of Michigan, Ann Arbor, fredblow@umich.edu \\ Elizabeth M. Hill \\ University of Michigan, Ann Arbor
}

Follow this and additional works at: https://digitalcommons.unl.edu/psychfacpub

Part of the Psychology Commons

Stoltenberg, Scott F.; Mudd, Sharon A.; Blow, Frederic C.; and Hill, Elizabeth M., "Evaluating Measures of Family History of Alcoholism: Density versus Dichotomy" (1998). Faculty Publications, Department of Psychology. 1026.

https://digitalcommons.unl.edu/psychfacpub/1026

This Article is brought to you for free and open access by the Psychology, Department of at DigitalCommons@University of Nebraska - Lincoln. It has been accepted for inclusion in Faculty Publications, Department of Psychology by an authorized administrator of DigitalCommons@University of Nebraska - Lincoln. 
Published in Addiction 93:10 (October 1998), pp. 1511-1520; doi: 10.1046/j.1360-0443.1998.931015117.x Copyright (c) 1998 Society for the Study of Addiction to Alcohol and Other Drugs. Published by Wiley. Used by permission.

Submitted September 19, 1997; revised December 8, 1997; accepted March 3, 1998; published online May 3, 2002.

\title{
Evaluating Measures of Family History of Alcoholism: Density versus Dichotomy
}

\author{
Scott F. Stoltenberg, Sharon A. Mudd, Frederic C. Blow, \\ and Elizabeth M. Hill
}

University of Michigan Alcohol Research Center, Ann Arbor, Michigan, USA

Corresponding author - Scott F. Stoltenberg, University of Michigan Alcohol Research Center, Department of Psychiatry, 400 East Eisenhower Parkway, Suite 2A, Ann Arbor, MI 48108-3318, USA

\begin{abstract}
Aims: Studies have used myriad measures of family history of alcoholism (FH) making it difficult to compare them directly. Commonly used FH measures partition samples into the well-known positive $(\mathrm{FH}+)$ and negative ( $\mathrm{FH}-$ ) dichotomy, although quantitative measures of density potentially provide more information. A standard $\mathrm{FH}$ measure would facilitate between-study comparisons. The purpose of this study is to evaluate a quantitative FH measure, called Family History Density (FHD), that has theoretical and practical advantages over currently used measures. Design: Logistic regression equations were estimated for FHD and six commonly used FH measures on alcohol dependence diagnosis and two measures of alcoholism severity (i.e., withdrawal and tolerance). Participants: Subjects recruited for studies (254 men and 97 women) completed a structured clinical assessment. Measurements: Alcoholism diagnosis and endorsement of tolerance or withdrawal symptoms were obtained using the alcohol module from the NIMH Diagnostic Interview Schedule III-R (DIS III-R). Family history of alcoholism was coded using the criteria from the Family Informant Schedule and Criteria (FISC). Findings: All FH measures were associated with alcohol dependence diagnosis, development of tolerance, and experiencing withdrawal symptoms in men. In women, only FHD and Parent were significantly associated with all three outcomes. Conclusions: FHD is a good candidate to be a standard FH measure because it is quantitative, based on familial relatedness, and capable of accounting for significant variation in alcoholism diagnosis and two indices of alcoholism severity in men and in women.
\end{abstract}




\section{Introduction}

Substantial evidence supports the long-held notion that alcoholism runs in families; however, while having a relative with alcoholism increases an individual's chances of developing alcoholism, it does not guarantee that outcome (Cotton, 1979). Alcoholism is much like other psychopathologies in that no simple Mendelian pattern of inheritance exists; it is a complex trait (Lander \& Schork, 1994; Schuckit, 1994).

Family history of alcoholism $(\mathrm{FH})$ has proved to be a robust index of risk for developing the disorder. Of course, $\mathrm{FH}$ measures do not provide a pure measure of genetic influence because, in a family, genes and family environment are confounded. Although such a caveat is likely to be found in every article written about FH measures, there is a tendency to think of FH measures as indices of "quasigenetic" effects (Alterman, 1988). We would like to emphasize that FH measures are better thought of as indices of "biopsychosocial" risk, explicitly recognizing that FH measures encompass a rich medley of intertwined vulnerability factors (see Zucker, 1987).

There is no FH measure that is generally accepted as the standard, although there has been interest in identifying one (Alterman, 1988; Turner et al., 1993). The studies listed in Table 1, found in a nonexhaustive search of the alcohol literature, report a variety of FH measures. Several of the measures partition samples into the well-known $\mathrm{FH}+$ and $\mathrm{FH}-$ dichotomy, although a few (Degree, Lineal, FPA, and FEA) produce multiple categories or quantitative scores.

One of the most commonly used FH measures partitions on the basis of alcoholism in the father. For the measure Father, $\mathrm{FH}+$ is defined as having a father with alcohol abuse or dependence and, in an effort to obtain groups of subjects that are at the extremes of risk, $\mathrm{FH}$ - is sometimes defined as having no first- or second-degree relative with alcohol abuse or dependence (e.g., Schuckit \& Smith, 1996). Schuckit's group has shown that sons of alcoholics differ from those with no first- or second-degree alcoholic relatives on a variety of characteristics, most notably their level of reaction to alcohol (Schuckit \& Smith, 1996). This partitioning, however, eliminates from study those individuals who do not have a father with alcoholism but do have other first- or second-degree relatives with alcoholism.

A measure that includes information on both parents (Parent) where having neither parent with alcoholism will be scored as FH-, thereby including subjects who were excluded with the measure Father. The definition of FH+ for Parent has not been consistent across studies. For example, $\mathrm{FH}+$ has been defined as having at least one parent with alcoholism (e.g., Nirenberg et al., 1990; Rogosch, Chassin \& Sher, 1990), or as having a father or mother in treatment for alcoholism (Ohannessian \& Hesselbrock, 1995). 


\begin{tabular}{|c|c|}
\hline Measure of family history & Studies \\
\hline Father alcoholic & $\begin{array}{l}\text { Schuckit \& Smith, 1996; Schuckit, 1994; Sayette et al., 1994; } \\
\text { Martin \& Sher, 1994; Sher et al., } 1991\end{array}$ \\
\hline Any 1st degree relative alcoholic & Drake et al., 1995; Wiesbeck et al., 1995; Schafer et al., 1991 \\
\hline Any blood relative alcoholic & Harford \& Parker, 1994 \\
\hline $\begin{array}{l}\text { Paternal or sibling plus 2nd degree relative } \\
\text { alcoholic }\end{array}$ & Hesselbrock \& Hesselbrock, 1992 \\
\hline $\begin{array}{l}\text { Father alcoholic, but no alcohol problem on } \\
\text { maternal side }\end{array}$ & Lex et al., 1994 \\
\hline Either parent alcoholic & Rogosch et al., 1990 \\
\hline At least one alcoholic parent & Nirenberg et al., 1990 \\
\hline $\begin{array}{l}\text { Biological father OR sibling plus additional } \\
\text { 2nd degree relative alcoholic }\end{array}$ & Gillen \& Hesselbrock, 1992 \\
\hline $\begin{array}{l}\text { At least one primary (mother, father, sibling) } \\
\text { and one secondary (aunt, uncle, grand- } \\
\text { parent) or } 3 \text { secondary relatives alcoholic }\end{array}$ & Garland, Parsons \& Nixon, 1993 \\
\hline Father OR mother in treatment for alcoholism & Ohannessian \& Hesselbrock, 1995 \\
\hline $\begin{array}{l}\text { Alcoholic father, paternal grandfather, and at } \\
\text { least one other alcoholic male on paternal side }\end{array}$ & $\begin{array}{l}\text { Finn \& Pihl, 1987; Finn \& Pihl, 1988; Conrod, Pihl \& Ditto, } \\
\quad 1995\end{array}$ \\
\hline Strong, moderate, weak & Reed, Grant \& Adams, 1987 \\
\hline Degree & $\begin{array}{l}\text { Harford, Parker \& Grant, 1992; Harford, 1992; Dawson et al., } \\
\text { 1992; Alterman, } 1988\end{array}$ \\
\hline Lineal & $\begin{array}{l}\text { Alterman et al., 1987; Hesselbrock, Hesselbrock \& Stabenau, } \\
\text { 1985; Stabenau, } 1984\end{array}$ \\
\hline Family Patterns of Alcoholism (FPA) & Turner et al., 1993 \\
\hline Family Expression of Alcoholism (FEA) & Zucker et al., 1994 \\
\hline
\end{tabular}

The measure First Degree is obtained by adding siblings to the Parent measure. For First Degree, $\mathrm{FH}+$ is defined as having any first-degree relative (biological parent or sibling) with alcoholism. FH- for First Degree has been defined as having no first-degree relative with alcoholism (Schafer et al., 1991; Wiesbeck et al., 1995), or as having no first- or seconddegree relatives with alcoholism (Drake et al., 1995). Father, Parent and First Degree are all dichotomous FH measures.

Degree, based on Alterman's (1988) four-category Generational Classification, extends First Degree to include information on second-degree relatives for $\mathrm{FH}+$. The four categories have been defined by Dawson, Harford \& Grant (1992) as follows: FHN = no biological relatives reported as problem drinkers or alcoholics, FHP1 $=$ alcoholism reported only in second- or third-degree relatives, FHP2 = alcoholism reported only in first-degree relatives, FHP3 $=$ alcoholism reported in both first- and second- or third-degree biological relatives.

Alterman et al., (1987) used a measure, called Lineality, that indicated the number of sides of the family that contained relatives with alcoholism. Lineality is a three-category measure with (1) nonlineal = no history of alcoholism in parents or grandparents, (2) unilineal $=$ with alcoholism reported in parents or grandparents from only one side of the family, and (3) bilineal = with alcoholism reported in parents or grandparents on both sides of the family. 
Turner et al. (1993) introduced family pattern of alcoholism (FPA) analysis where each family member (grandparents, parents, aunts, uncles, brothers, sisters, sons, and daughters) was rated as either (1) an abstainer, (2) a nonproblem drinker, or (3) a problem drinker. Parents and grandparents were given a score of 1 if they were rated as a problem drinker and a score of 0 otherwise. To control for number of aunts, uncles, and siblings for each category, the proportion of problem drinkers to the total membership in that category is calculated. FPA is a quantitative measure consisting of the sum of scores of all reported relatives.

Turner et al. (1993) compared FPA to several measures of family history in the literature and found that FPA explained more variance in age of onset of alcoholism, consequences of drinking and alcoholism severity in male veteran inpatients than did any of the other measures. Clearly, this study suggests the value of moving away from a multitude of family history measures toward a standard that is quantitative and therefore amenable to more sophisticated statistical analysis.

Heterogeneity in FH measures makes it difficult to compare studies, although indexing vulnerability to alcoholism appears to be effective with any of these measures. This review was not intended to be exhaustive but to illustrate the diversity of $\mathrm{FH}$ measures in the literature. Adopting a standard FH measure would facilitate comparisons between studies.

We propose a new FH measure called Family History Density (FHD) that is essentially a modification of FPA, with a weighting scheme based on familial relatedness (Zucker, Ellis \& Fitzgerald 1994). The present study evaluates the performance of FHD and that of various other FH measures on the capacity to predict measures of alcohol dependence (alcoholism diagnosis; development of tolerance and experience of withdrawal symptoms) in both men and women. These analyses include FH measures that represent those commonly found in the alcohol literature chosen to reflect various levels of information content. We hypothesize that FHD will be associated with measures of alcohol dependence in both men and women.

\section{Methods}

\section{Subjects}

The study sample was obtained from a comprehensive database of 1,583 individuals who were recruited from community $(41 \%)$, alcoholism treatment $(49 \%)$, and medical hospital $(10 \%)$ settings for a variety of research studies at the University of Michigan Alcohol Research Center (UMARC) during 1989-95. Individuals from the community included those with and without a history of alcohol problems. Study participants from the alcoholism treatment and medical hospital settings included individuals with a history of alcohol problems with or without other drug-use problems. After a brief screening interview, those who consented and were eligible for further studies were given the structured diagnostic interview analyzed herein. Patients from alcohol treatment centers were initially screened via chart review, which generally excluded subjects known to have psychiatric disorders that required treatment with medication, such as schizophrenia or manic depression. Participants resemble local county residents in education, race, and marital status (see 
Hill et al., 1997 for a more detailed description of sample characteristics and recruitment methods).

Only those who provided alcohol problem data on each of their six direct biological ancestors (mother, father, all four grandparents) were included in the study sample ( $n=$ 351). Most subjects with missing values responded "Don't know" about the drinking history of one or more relatives, possibly due to their lack of exposure to those relatives. An approach to include more subjects would be to score a "Don't know" as nonalcoholic, however, to maximize the accuracy of the family history measures, we avoided inclusion of subjects with missing family history information.

Those in the study sample were not significantly different from the complete UMARC sample on the primary measures of interest for this study: mean number of alcohol symptoms, lifetime development of tolerance or experiencing withdrawal, or age of alcoholism onset (data not shown), with one exception. The subsample of women had slightly fewer mean alcohol dependence symptoms ([mean \pm SD] $2.86 \pm 3.19)$ than did the complete sample $(3.04 \pm 3.27), t(517)=2.17, p<0.05$.

\section{Measures of subject characteristics}

Alcohol abuse or dependence diagnosis was made by using the alcohol module from the NIMH Diagnostic Interview Schedule III-R (DIS III-R) (Robins et al., 1981). The DIS III-R assesses symptomatology based on the DSM-III-R, allowing for individual symptom counts and dates of earliest and most recent occurrence of individual symptoms. Lifetime development of tolerance was assessed by endorsement of the question "Did you ever get tolerant to alcohol, that is you needed to drink a lot more in order to get an effect, or found that you could no longer get high on the amount you used to drink?" Lifetime experience of withdrawal symptoms was assessed by endorsement of the question "People who cut down or stop drinking after drinking for a considerable time often have withdrawal symptoms. Common ones are the 'shakes' (hands tremble), being unable to sleep, feeling anxious or depressed, sweating, heart beating fast or the DTs or seeing or hearing things that aren' $t$ really there. Have you had any problems like that when you stopped or cut down on drinking?" Tolerance and withdrawal were selected for analysis because they represent diagnostically important measures of alcoholism severity. All demographic data except for occupational prestige were determined using the DIS III-R. Occupational socioeconomic status (i.e., occupational prestige) ratings were based on the indexes for MSE12 census occupational categories (Featherman \& Stevens, 1982).

\section{Family history measures}

Family history of alcoholism was assessed during interviews with the participant. A pedigree was constructed, showing children, parents, siblings, aunts, uncles, and grandparents. For each relative, level of alcohol use was assigned (abstinent, social drinker, and probable or definite alcoholism). Alcoholism was coded using the criteria from the Family Informant Schedule and Criteria (FISC, Mannuzza et al., 1985). Probable alcoholism was coded when the respondent could give examples of the relative being frequently drunk, drinking regularly, and heavily, or "always had a glass in his hand." Definite was coded if the respondent could also name specific consequences from the FISC list (legal, marital, 
work, or health problems, fights when drunk, or alcoholism treatment). In the present analysis "probable" and "definite" codes were collapsed. Hill et al. (1994) analyzed the roles of several traditional FH measures on alcohol consumption and dependence in a partially overlapping sample of UMARC participants. We chose to evaluate FHD relative to six FH measures that have been used in previous research. Based on these self-report data, we assigned each subject a score for each of the following family history measures:

a) Father: Dichotomous variable assessing whether the subject has an alcoholic father $(0=$ no first- or second-degree alcoholic relatives; $1=$ alcoholic father $)$.

b) Parent: Dichotomous variable assessing whether the subject has any parent with alcoholism ( $0=$ neither parent alcoholic; $1=$ alcoholic father, mother, or both).

c) First degree: Dichotomous variable indicating whether the subject had any alcoholic first-degree relatives $(0=$ no alcoholic parents or siblings; $1=$ one or more alcoholic parents or siblings).

d) Lineal: A three-level variable indicating the number of sides of the family in which there is a history of alcoholism $(0=$ none, $1=$ paternal or maternal; $2=$ paternal and maternal).

e) Degree: A four-level variable indicating density of familial alcoholism $(0=$ no alcoholic first- or second-degree relatives; 1 = only second-degree alcoholic relatives; 2 = only first-degree alcoholic relatives; 3 = both first- and second-degree alcoholic relatives).

f) Family pattern analysis (FPA): FPA score was calculated as in Turner et al., (1993) where alcoholic parents and grandparents were each given a score of 1 and nonalcoholic parents and grandparents were each given scores of 0 . Scores for aunts, uncles, and siblings were the percentages of alcoholics in each sibship. For each subject, FPA scores were summed across relatives. In the present analyses FPA scores ranged from 0 to 9.67.

g) Family history density (FHD): FHD score was based on degree of relatedness where both parents (each $=0.5$ ) and all four grandparents $(e a c h=0.25)$ were considered (see Zucker et al., 1994). Nonalcoholic relatives were given a score of 0 , alcoholic relatives were given a score based on their relatedness (e.g., alcoholic father $=0.5$; alcoholic grandmother $=0.25$ ). Those scores were summed over the six direct ancestors to obtain FHD scores that range from 0 to 2 .

\section{Statistical analysis}

Logistic regression equations were estimated, separately by gender, for each of the $\mathrm{FH}$ measures on: (1) DSM-III-R lifetime diagnosis of alcoholism, defined as alcohol dependence or abuse; DSM-III-R symptom of (2) tolerance and (3) withdrawal. Men and women were analyzed separately. Logistic, rather than general linear, regression was employed because the dependent variables were either ordinal but not normally distributed (alcoholism diagnosis) or dichotomous (tolerance and withdrawal). Alcoholism diagnosis for each subject was analyzed as follows: $1=$ no alcohol abuse/dependence, $2=$ alcohol abuse only, $3=$ mild alcohol dependence, $4=$ moderate alcohol dependence, $5=$ severe alcohol dependence (Robins et al., 1981). For both tolerance and withdrawal, if the subject reported experiencing the symptom in their lifetime, they were given a score of 1 ; if not, they were 
given a score of 2. Table 2 presents the frequency distributions and percentages of men and women across the three outcome categories.

Table 2. Frequency distributions and percentages of categorical outcomes for males and females (see text for category descriptions)

\begin{tabular}{|c|c|c|c|c|}
\hline \multirow[b]{2}{*}{ Alcoholism diagnosis } & \multicolumn{2}{|c|}{ Males $(n=254)$} & \multicolumn{2}{|c|}{ Females $(n=97)$} \\
\hline & Frequency & $\%$ & Frequency & $\%$ \\
\hline 1 & 93 & 36.6 & 55 & 56.7 \\
\hline 2 & 3 & 1.2 & 3 & 3.1 \\
\hline 3 & 6 & 2.4 & 4 & 4.1 \\
\hline 4 & 50 & 19.7 & 16 & 16.5 \\
\hline 5 & 102 & 40.2 & 19 & 19.6 \\
\hline Tolerance $^{\mathrm{a}}$ & 126 & 50.8 & 32 & 36.0 \\
\hline Withdrawala & 110 & 44.4 & 23 & 25.8 \\
\hline
\end{tabular}

aPercentage of lifetime symptom endorsement

Models were judged on whether their standardized regression coefficients were significantly different from zero. Results of the various models were not directly compared with each other because the predictors were highly correlated. For descriptive purposes, goodness-of-fit was judged using the area under the receiver operating characteristic (ROC) curve. ROC curves are created by plotting sensitivity (accuracy for predicting events), versus one minus specificity (accuracy for predicting nonevents). The greater the area under the ROC curve (values can range from 0.5 to 1.0), the better the explanatory power of the logistic regression model (see Hanley \& McNeil, 1982).

\section{Results}

Mean age for the men $(n=254)$ was $49.4( \pm 15.7)$. For the 97 women, the mean age was 51.1 ( \pm 17.6). The majority of the sample was Caucasian (91.5\% men, $95.8 \%$ women). Subjects were recruited from a variety of settings with men and women differing in recruitment source $\left(\chi^{2}=13.9,2 \mathrm{df}, p<0.001\right)$. Significantly more men $(45 \%)$ than women $(23 \%)$ came from alcoholism treatment settings, while more women $(62 \%)$ than men $(45 \%)$ came from community settings. There were no gender differences in the number of subjects coming from medical hospital settings ( $8 \%$ men, $13 \%$ women).

Despite these differences in subject source, there were no gender differences in marital status $(83.5 \%$ ever married for men, $82.3 \%$ for women, $Z=0.3$, NS), or in mean occupational prestige ratings ( $43.4 \pm 23.5$ for men, $46.9 \pm 17.6$ for women, $t(230)=1.50, p=0.13$ ), although women had higher average educational levels than men $(14.9 \pm 2.1$ years of education and $14.2 \pm 2.5$, respectively, $t(340)=2.63, p=0.009$ ).

In the study sample, men were diagnosed more frequently than women as having either alcohol abuse or dependence $(63.4 \%$ and $43.3 \%$, respectively, see Table 2$)$, and more men than women reported developing tolerance (50.8\% and $36.0 \%$, respectively) and experiencing withdrawal symptoms $(44.4 \%$ and $25.8 \%)$ at some time in their lives. These gender differences are consistent with the fact that more men than women in this sample were 
recruited from treatment sources, and with previously observed gender differences in the prevalence of alcoholism (e.g., Kessler et al., 1994).

\section{Alcoholism diagnosis}

In Table 3, FH measures are sorted in descending order based on their relative information content. That is, those measures that are quantitative or multicategorical are listed above dichotomous measures. Table 3 contains the area under the ROC curve and the standardized parameter estimates for the ordinal logistic regressions of FH measures on alcoholism diagnosis. For males, all standardized beta weights are significantly different from zero. FPA $(69.0 \%)$ and Father $(68.6 \%)$ appear to be the most robust predictors of alcohol dependence diagnosis in men, followed by Degree $(65.4 \%)$, Lineal (63.8\%), FHD (63.3\%), First Degree $(60.5 \%)$, and Parent $(58.3 \%)$.

Table 3. Goodness of fit of logistic regression models for measures of family history of alcoholism

\begin{tabular}{|c|c|c|c|c|c|c|}
\hline & \multicolumn{2}{|c|}{$\begin{array}{c}\text { Alcohol dependence } \\
\text { diagnosis }\end{array}$} & \multicolumn{2}{|c|}{ Tolerance } & \multicolumn{2}{|c|}{ Withdrawal } \\
\hline & $\begin{array}{c}\text { Area under } \\
\text { curve }^{\mathrm{a}}\end{array}$ & $\begin{array}{l}\text { Parameter } \\
\text { estimate }\end{array}$ & $\begin{array}{l}\text { Area under } \\
\text { curve }\end{array}$ & $\begin{array}{c}\text { Parameter } \\
\text { estimate }\end{array}$ & $\begin{array}{l}\text { Area under } \\
\text { curve }\end{array}$ & $\begin{array}{c}\text { Parameter } \\
\text { estimate }\end{array}$ \\
\hline Males & \multicolumn{2}{|c|}{$(N=254)$} & \multicolumn{2}{|c|}{$(N=248)$} & \multicolumn{2}{|c|}{$(N=248)$} \\
\hline FPA & 69.0 & $0.45^{\ddagger}$ & 62.7 & $0.24^{+}$ & 71.8 & $0.47 \ddagger$ \\
\hline FHD & 63.3 & $0.31 \ddagger$ & 58.7 & $0.16^{*}$ & 65.6 & $0.34^{\ddagger}$ \\
\hline Degree & 65.4 & $0.36^{\ddagger}$ & 60.6 & $0.20^{+}$ & 67.5 & $0.36^{\ddagger}$ \\
\hline Lineal & 63.8 & $0.34^{\ddagger}$ & 59.0 & $0.19^{+}$ & 63.9 & $0.30 \ddagger$ \\
\hline First degree & 60.5 & $0.27 \ddagger$ & 56.6 & $0.15^{*}$ & 63.0 & $0.30 \ddagger$ \\
\hline Parent & 58.3 & $0.23 \ddagger$ & 56.0 & $0.15^{*}$ & 59.9 & $0.24 \ddagger$ \\
\hline Father & 68.6 & $0.52 \ddagger$ & 63.8 & $0.32^{+}$ & 72.1 & $0.56 \ddagger$ \\
\hline Females & \multicolumn{2}{|c|}{$(N=97)$} & \multicolumn{2}{|c|}{$(N=89)$} & \multicolumn{2}{|c|}{$(N=89)$} \\
\hline FPA & 60.5 & $0.28^{+}$ & 60.6 & 0.19 & 66.3 & $0.31^{*}$ \\
\hline FHD & 64.1 & $0.34^{+}$ & 65.1 & $0.30^{*}$ & 65.6 & $0.26^{*}$ \\
\hline Degree & 56.5 & 0.15 & 60.4 & 0.22 & 62.5 & 0.26 \\
\hline Lineal & 56.0 & 0.14 & 53.9 & 0.08 & 55.7 & 0.12 \\
\hline First degree & 57.7 & 0.20 & 63.0 & $0.29^{*}$ & 62.3 & $0.27^{*}$ \\
\hline Parent & 61.5 & $0.34 \ddagger$ & 63.3 & $0.34^{+}$ & 66.3 & $0.39^{*}$ \\
\hline Father & 57.4 & 0.20 & 60.6 & 0.24 & 61.7 & 0.27 \\
\hline
\end{tabular}

aReceiver operating characteristic. ${ }^{*} p<0.05,{ }^{+} p<0.01, \ddagger p<0.001$

In females, FHD, Parent, and FPA are associated with alcoholism diagnosis as shown by statistically significant standardized beta weights. FHD accounts for the largest area under the ROC curve (64.1\%) followed by Parent (61.5\%) and FPA (60.5\%). None of the other FH measures are significantly associated with alcoholism diagnosis in women.

\section{Tolerance}

Table 3 presents the area under the ROC curves and standardized beta weights for the logistic regressions of FH measures on development of tolerance for males and for females. 
For males, all FH measures are significantly associated with development of tolerance. Father $(63.8 \%)$ and FPA $(62.7 \%)$ appear to be the strongest predictors of tolerance in men, followed by Degree (60.6\%), Lineal (59.0\%), FHD (58.7\%), First Degree (56.6\%), and Parent (56.0\%).

For females FHD, Parent, and First Degree are significantly associated with development of tolerance explaining $65.1 \%, 63.3 \%$, and $63.0 \%$ of the area under the ROC curve, respectively. None of the other FH measures are significantly associated with the development of tolerance in our sample of women.

\section{Withdrawal}

Table 3 presents the area under the ROC curves and the standardized beta weights for the logistic regressions of $\mathrm{FH}$ measures on lifetime experience of withdrawal symptoms for males and for females. All FH measures have significant standardized parameter estimates for males. Father $(72.1 \%)$ and FPA $(71.8 \%)$ appear to be the best predictors of withdrawal in men closely followed by Degree (67.5\%), Lineal (63.9\%), FHD (65.6\%), First Degree (63.0\%), and Parent (59.9\%).

For females, FPA and Parent both accounted for $66.3 \%$ of the area under the ROC curve, while FHD accounted for $65.6 \%$ and First Degree $62.3 \%$. None of the other FH measures were associated with withdrawal in women.

\section{Discussion}

In this study all seven FH measures were significantly associated with alcoholism diagnosis, development of tolerance, and experience of withdrawal in men. In women only FHD and Parent were significantly associated with all three outcome measures. Because of the theoretical advantages of FHD, these results suggest that it should be considered when selecting an FH measure, especially when both men and women are to be studied.

Because FH is a robust index of vulnerability for alcoholism and because many studies have a family history component, there has been interest in developing a standard FH measure. Alterman (1988) found the Lineal classification to be an advance over dichotomous FH measures. Turner et al. (1993) reported that Family Patterns of Alcoholism (FPA) explained more variance in consequences, dependence, and age of onset of alcoholism than did dichotomous FH measures. In the present analyses (as in Turner et al., 1993), FPA outperforms Lineal in men. In the present study, FPA outperformed Lineal in women, although neither Alterman (1988) nor Turner et al. (1993) studied women. FPA appears to be a real advance in the measurement of $\mathrm{FH}$.

Although FHD is based on FPA, there are two subtle, but important, differences between them. First, FHD uses information from only parents and grandparents, i.e., direct ancestors, whereas FPA uses information about many relatives including aunts, uncles, and siblings. By not including information from aunts and uncles to calculate FHD, even though they are as genetically informative as grandparents, we are underscoring the position that $\mathrm{FH}$ measures are not measures of genetic risk but of biopsychosocial risk. In this context, grandparents are not interchangeable with aunts and uncles because grand parents have greater potential influence. Grandparents establish and maintain the rearing 
conditions of parents, aunts, and uncles. Therefore, grandparents have a more direct path of influence than do aunts and uncles. In fact, some of the influence of aunts and uncles on the proband may be thought of as being indirect effects of the grandparents mediated through the aunts and uncles. A similar argument can be made for sibling and parental effects. Secondly, the weighting system for FHD is based on familial relatedness, whereas FPA uses arbitrary dummy codes $(0,1)$ and percentages. Weighting by familial relatedness is functionally the same as weighting by genetic relatedness (i.e., parents $=0.50$, grandparents $=0.25$ ) but is theoretically distinct because it explicitly takes into account hypothesized influence of family environment. That is, in general parents can be expected to have more direct influence than grandparents (although some of the parental effect can also be thought of as indirect influence of grandparents).

By including mothers in the scoring of FHD, we risk confounding effects on our outcome variables with deleterious effects associated with drinking during pregnancy including, but not limited to, fetal alcohol syndrome (FAS). Because FH measures, such as FHD, are indices of biopsychosocial risk in the fullest sense, the deleterious effects of drinking during pregnancy should be included. Only if one considers FH to be an index of genetic effects should mothers not be included. However, failing to consider the effects of drinking during pregnancy may result in a biased assessment of biopsychosocial risk.

One limitation of this study involves the use of self-report accounts to measure family history of alcoholism. When compared to family history diagnosis of other psychiatric disorders, self-reports of family history of alcoholism appear to be less biased and relatively reliable (Adreason et al., 1986). Probands with a history of major depression or generalized anxiety tend to overreport the same diagnosis in their parents (Kendler et al., 1991); however, the existence of this bias has not been strongly supported for alcoholism (Dawson et al., 1992; Crum \& Harris, 1996). It appears that family history of alcoholism data is adequately reliable and not overly prone to bias. Another limitation of this study is that we were unable to directly compare the FH measures statistically. Given the large sample sizes required to have sufficient statistical power to detect small differences in the area under the ROC curve (Hanley \& McNeil, 1982), we use these areas for descriptive purposes only. A one-tailed test $(\alpha=0.05)$ for the difference between $70 \%$ and $75 \%$ would require 652 subjects per group to have $80 \%$ power. The generalizability of FHD to other countries and cultures is not obvious. Certainly, transmission of genetic material from grandparents to parents to proband does not vary, but familial patterns of social transmission are less stable across cultures. Multicategory or continuously varying measures confer statistical advantages over dichotomous measures that are culture-free; therefore, the results of the present study are generalizable in that respect.

Our results do not indicate that FHD represents a great improvement in the assessment of biopsychosocial vulnerability to alcoholism over other methods of measuring $\mathrm{FH}$ in males. In fact, the dichotomous measure Father outperformed all other FH measures in males. The measure Father, however, has two drawbacks: (1) it is dichotomous, and (2) its strict definition of FH (no first- or second-degree relatives with alcoholism) eliminates many potential subjects from analysis. In studies designed to compare high and low risk men, Father appears to be a very good measure. However, our results suggest that Father is not a good measure of risk in women. Clearly, study design should inform choice of FH 
measure. However, it should be noted that while an index of risk similar to Father can be derived from FHD scores (low FHD $=0$; high FHD $\geq 0.75$ ), one cannot derive FHD scores from Father. Parent performed surprisingly well in both men and women. However, it too is a dichotomous measure and is less commonly used than Father. In studies designed to use FH as a covariate in modeling, quantitative, multigenerational (Finn \& Pihl, 1988) measures such as FPA or FHD would be preferable. When women are considered, our results indicate that FHD would be a better choice than FPA. Future research could evaluate whether FHD is as effective as Father at classifying at-risk individuals. Because self-report of family history of alcoholism appears to be relatively reliable (Andreason et al., 1986), future work could include the development of a self-report instrument to assess FHD. Although direct personal interview is the ideal method of collecting family history data, it is not always possible. A self-report questionnaire designed to assess FHD could facitlitate the use of FHD as a standard FH measure.

Acknowledgments - The authors wish to thank the staff at UMARC for all of their efforts; Myra Kim $\mathrm{PhD}$ for statistical advice; and anonymous reviewers for helpful comments. A portion of this paper was presented at the 1997 Annual Meeting of the Research Society on Alcoholism. This work was supported by NIAAA grants P50 AA0738, R21 AA10696, and T32 AA07477.

\section{References}

Alterman, A. I. (1988) Patterns of familial alcoholism, alcoholism severity and psychopathology, Journal of Nervous and Mental Disorders, 176, 167-175.

Alterman, A. I., Gerstley, L. J., Goldstein, G. \& Tarter, R. E. (1987) Comparisons of the cognitive functioning of familial and nonfamilial alcoholics, Journal of Studies on Alcohol, 48, 425-429.

Andreasen, N. C., Rice, J., Endicott, J., Reich, T. \& Coryell, W. (1986) The family history approach to diagnosis: how useful is it? Archives of General Psychiatry, 43, 421-429.

Conrod, P. J., Pihl, R. O. \& Ditto, B. (1995) Autonomic reactivity and alcohol-induced dampening in men at risk for alcoholism and men at risk for hypertension, Alcoholism: Clinical and Experimental Research, 19, 482-489.

Cotton, N. S. (1979) The familial incidence of alcoholism: a review, Journal of Studies on Alcohol, 40, $89-116$.

Crum, R. M. \& Harris, E. L. (1996) Risk of alcoholism and parental history: gender differences and a possible reporting bias, Genetic Epidemiology, 13, 329-341.

Dawson, D. A., Harford, T. C. \& Grant, B. F. (1992) Family history as a predictor of alcohol dependence, Alcoholism: Clinical and Experimental Research, 16, 572-575.

Drake, A. I., Butters, N., Shear, P. K. et al. (1995) Cognitive recovery with abstinence and its relationship to family history for alcoholism, Journal of Studies on Alcohol, 56, 104-109.

Featherman, D. L. \& Stevens, G. (1982) A revised socioeconomic index of occupational status: application in analysis of sex differences in attainment, in: R. M. Hauser et al. (Ed.) Social Structure and Behavior: Essays in Honor of William Hamilton Sewell (New York, Academic Press).

Finn, P. R. \& Pihl, R. O. (1987) Men at high risk for alcoholism: the effect of alcohol on cardiovascular response to unavoidable shock, Journal of Abnormal Psychology, 96, 230-236. 
Finn, P. R. \& Pihl, R. O. (1988) Risk for alcoholism: a comparison between two different groups of sons of alcoholics on cardiovascular reactivity and sensitivity to alcohol, Alcoholism: Clinical and Experimental Research, 12, 742-747.

Garland, M. A., Parsons, O. A. \& Nixon, S. J. (1993) Visual-spatial learning in nonalcoholic young adults with and those without a family history of alcoholism, Journal of Studies on Alcohol, 54, 219-224.

Gillen, R. \& Hesselbrock, V. (1992) Cognitive functioning, ASP and family history of alcoholism in young men at risk for alcoholism, Alcoholism: Clinical and Experimental Research, 16, 206-214.

Hanley, J. A. \& McNeil, B. J. (1982) The meaning and use of the area under a receiver operating characteristic (ROC) curve, Radiology, 143, 29-36.

Harford, T. C. (1992) Family history of alcoholism in the United States: prevalence and demographic characteristics, British Journal of Addiction, 87, 931-935.

Harford, T. C. \& Parker, D. A. (1994) Antisocial behavior, family history and alcohol dependence symptoms, Alcoholism: Clinical and Experimental Research, 18, 265-268.

Harford, T. C., Parker, D. A. \& Grant, B. F. (1992) Family history, alcohol use and dependence symptoms among young adults in the United States, Alcoholism: Clinical and Experimental Research, 16, 1042-1046.

Hesselbrock, M. N. \& Hesselbrock, V. M. (1992) Relationship of family history, antisocial personality disorder and personality traits in young men at risk for alcoholism, Journal of Studies on Alcohol, 53, 619-625.

Hesselbrock, V. M., Hesselbrock, M. N. \& Stabenau, J. R. (1985) Alcoholism in men patients subtyped by family history and antisocial personality, Journal of Studies on Alcohol, 46, 59-64.

Hill, E. M., Blow, F. C., Young, J. P. \& Singer, K. M. (1994) Family history of alcoholism and childhood adversity: joint effects on alcohol consumption and dependence, Alcoholism: Clinical and Experimental Research, 18, 1083-1090.

Hill, E. M., Ross, L. T., Mudd, S. A. \& Blow, F. C. (1997) Adulthood functioning: the joint effects of parental alcoholism, gender and childhood socioeconomic stress, Addiction, 92, 583-596.

Kendler, K. S., Silberg, J. L., Neale, M. C., Kessler, R. C., Heath, A. C. \& Eaves, L. J. (1991) The family history method: whose psychiatric history is measures? American Journal of Psychiatry, 148, 15011504.

Kessler, R. C., McGonagle, K. A., Zhao, S., et al. (1994) Lifetime and 12-month prevalence of DSMIII-R psychiatric disorders in the United States: results from the National Comorbidity Survey, Archives of General Psychiatry, 51, 8-19.

Lander, E. S. \& Schork, N. J. (1994) Genetic dissection of complex traits, Science, 265, 2037-2048.

Lex, B. W., Rhoades, E. M., Teoh, S. K., Mendelson, J. H. \& Greenwald, N. E. (1994) Divided attention task performance and subjective effects following alcohol and placebo: differences between women with and without a family history of alcoholism, Drug and Alcohol Dependenc e, 35, 95-105.

Mannuzza, S., Fyer, A. J., Endicott, J. \& Klein, D. F. (1985) Family Informant Schedule and Criteria (FISC) (New York; Anxiety Disorders Clinic, New York State Psychiatric Institute).

Martin, E. D. \& Sher, K. J. (1994) Family history of alcoholism, alcohol use disorders and the fivefactor model of personality, Journal of Studies on Alcohol, 55, 81-90.

Nirenberg, T. D., Liepman, M. R., Begin, A. N., Maisto, S. A. \& Libermann, M. P. (1990) Family history of alcoholism in males: absence of distinguishing features for treatment matching, International Journal of the Addictions, 25, 1195-1209.

Ohannessian, C. M. \& Hesselbrock, V. M. (1995) Temperament and personality typologies in adult offspring of alcoholics, Journal of Studies on Alcohol, 56, 318-327. 
Reed, R., Grant, I. \& Adams, K. M. (1987 ) Family history of alcoholism does not predict neuropsychological performance in alcoholics, Alcoholism: Clinical and Experimental Research, 11, 340-344.

Robins, L. N., Helzer, J. H., Croughan, J., Williams, J. B. W. \& Spitzer, R. L. (1981) NIMH Diagnostic Interview Schedule: Version III (Rockville, MD, National Institute of Mental Health).

Rogosch, F., Chassin, L. \& Sher, K. J. (1990) Personality variables as mediators and moderators of family history risk for alcoholism: conceptual and methodological issues, Journal of Studies on Alcohol, 51, 310-318.

Sayette, M. A., Breslin, F. C., Wilson, G. T. \& Rosenblum, G. D. (1994 ) Parental history of alcohol abuse and the effects of alcohol and expectations of intoxication on social stress, Journal of Studies on Alcohol, 55, 214-223.

Schafer, K., Butters, N., Smith, T, et al., (1991) Cognitive performance of alcoholics: a longitudinal evaluation of the role of drinking history, depression, liver function, nutrition and family history, Alcoholism: Clinical and Experimental Research, 15, 653-660.

Schuckit, M. A. (1994) A clinical model of genetic influences in alcohol dependence, Journal of Studies on Alcohol, 55, 5-17.

Schuckit, M. A. \& Smith, T. L. (1996) An 8-year follow-up of 450 sons of alcoholic and control subjects, Archives of General Psychiatry, 53, 202-210.

Sher, K. J., Walitzer, K. S., Wood, P. K. \& Brent, E. E. (1991) Characteristics of children of alcoholics: putative risk factors, substance use and abuse, and psychopathology, Journal of Abnormal Psychology, 100, 427-448.

Stabenau, J. R. (1984) Implications of family history of alcoholism, antisocial personality, and sex differences in alcohol dependence, American Journal of Psychiatry, 141, 1178-1182.

Turner, W. M., Cutter, H. S. G., Worobec, T. G., O’Farrell, T. J., Bayog, R. D. \& Tsuang, M. T. (1993) Family history models of alcoholism: age of onset, consequences and dependence, Journal of Studies on Alcohol, 54, 164-171.

Wiesbeck, G. A., Mauerer, C., Thome, J., Jakob, F. \& Boening, J. (1995) Alcohol dependence, family history, and D2 dopamine receptor function as neuroendocrinologically assessed with apomorphine, Drug and Alcohol Dependence, 40, 49-53.

Zucker, R. A. (1987) The four alcoholisms: a developmental account of the etiological process, in: Rivers, P. C. (Ed.) Alcohol and Addictive Behaviors: Nebraska symposium on motivation, pp. 27-83 (Lincoln, NE, University of Nebraska Press).

Zucker, R. A., Ellis, D. A. \& Fitzgerald, H. E. (1994 ) Developmental evidence for at least two alcoholisms: I. Biopyschosocial variation among pathways into symptomatic difficulty, in: Babor, T. F., Hesselbrock, V., Meyer, R. E. \& Shoemaker, W. (Eds) Types of alcoholics: evidence from clinical, experimental, and genetic research, pp. 134-146 (New York, The New York Academy of Sciences). 